\title{
The Impact of Market Imperfections on Real Estate Returns and Optimal Investor Portfolios
}

\author{
Crocker H. Liu, New York University \\ Terry V. Grissom, Texas A\&M University \\ David J. Hartzell, University of North Carolina
}

This study investigates the consequences of several imperfections associated with real estate markets on pricing and optimal investor portfolios from a CAPM context. CAPM assumptions are relaxed to recognize illiquidity, the consumption and investment attributes of owner-occupied housing, and a mildly segmented market structure. The study finds that relaxing the CAPM assumptions lead to a separate pricing paradigm for financial assets, income-producing real estate and owner-occupied housing respectively, that a "dividend effect" arises for real estate as the result of illiquidity, and that illiquidity reduces the extent to which investors hold real estate in their portfolios.

\section{Introduction}

Most theoretical research on the investment decisions of investors and equilibrium asset prices focuses almost exclusively on financial assets although some literature exists on other asset classes such as human capital (c.f. Mayers [13] and Brito [5]) and durables (c.f. Bosch [3] and Grossman and Laroque [12]). One class of assets excluded from much theoretical inquiry in the past is real estate. The unstated implication is that the results of equilibrium asset pricing and investor's portfolio demand for stocks is directly applicable to real estate. However, real estate and the market within which it trades exhibit certain features that might distinguish the pricing of real estate from that of financial assets.

The purpose of this study is to use the capital asset pricing model (CAPM) framework to investigate what consequences arise from recognizing real estate imperfections on the pricing of real estate and other financial assets and on the composition of optimal investor portfolios. The standard assumptions of the CAPM are relaxed to recognize illiquidity, a mildly segmented market structure, and the consumption and investment attributes of owner-occupied housing. The relaxation of the CAPM 
assumptions leads to a separate pricing paradigm for financial assets, income-producing real estate, and owner-occupied houses, respectively.

A separate pricing paradigm arises in part because illiquidity is explicitly recognized, which leads to a "dividend effect" for real estate but not for stocks. Illiquidity causes real estate investors to bid up the price of real estate the higher the expected income yield because only the capital appreciation component of return is affected by illiquidity. Illiquidity also reduces the extent to which institutional investors use a surrogate for the owner-occupied housing market portfolio consisting of stocks, such as homebuilding, and property types, such as apartments, to imperfectly "span" a mildly segmented market structure. This mildly segmented market structure occurs because institutional investors can invest only in income-producing real estate, stocks, and bonds hut not owner-occupied houses, whereas individual investors are not restricted in their opportunity set.

A further finding of the current study is that although beta is still the appropriate measure of risk for financial assets and income- producing real estate, an additional measure of risk is associated with owner-occupied housing because of the mildly segmented market structure. However, the risk premium associated with systematic risk given a mildly segmented housing market is not identical to that if an integrated market exists.

The remainder of the paper proceeds as follows. Section two discusses characteristics that distinguish real estate from other assets, while section three reviews the previous variations of the CAPM that are incorporated in the current model. The next section of the paper develops a theoretical valuation model for real estate using past modifications to the CAPM as the initial point of departure. Portfolio demands associated with this model and implications of the resulting model are discussed in section five. Section six concludes the study. An appendix contains proofs of the central propositions of the model.

\section{Features that Distinguish Real Estate from Other Assets}

Several authors have recognized that the pricing of real estate might include factors not associated with other assets. ${ }^{1}$ Factors cited include hut are not limited to (1) the delivery of consumption services by owner-occupied housing, (2) illiquidity and transaction costs, (3) segmentation within the real estate market, (4) inelastic supply in the short run, and (5) no short sales.

\footnotetext{
${ }^{1}$ These authors include Draper and Findlay [8] among others.
} 
Real estate is similar to other durable assets in that it has the potential for delivering consumption services that might result in a conflict between the optimum amount of the asset held for investment purposes and the optimum amount sought for consumption. The property owner can consume these housing services even in the extreme case where the property is illiquid. Unlike some durables however, a rental market exists for real estate that allows one to resolve the consumption versus investment conflict through the trading of consumption flows. ${ }^{2}$

Another feature that distinguishes real estate from financial assets is that real estate is illiquid. Illiquidity in this paper is defined as the inability to make a quick sale at full market value. In other words, a quick sale can only he achieved at a significant price concession. However, only the capital appreciation but not the income component of the real estate return is subject to illiquidity. The illiquidity associated with real estate arises in part because the level and nature of transactions costs are higher for real estate than financial assets because agents must incur more time and costs to obtain real estate information and to search for buyers.

A mildly segmented market also characterizes real estate. The nature of this segmentation is analogous to that hypothesized to exist between domestic and international financial assets. ${ }^{3}$ Errunza and Losq [9] define a mildly segmented market structure as one in which there is

a two-country capital market where country 1 investors are restricted, country 2 investors are unrestricted, country 1 securities are eligible and country 2 securities are ineligible. Specifically, portfolio inflow restrictions imposed by the government of country 2 prevent country 1 investors from holding country 2 securities; whereas no such controls are imposed by the government of country 1. [pp. 107]

A mildly segmented market structure is hypothesized to exist for real estate because institutional investors are restricted from investing in the equity of owner-occupied housing which provides income

\footnotetext{
${ }^{2}$ Bosch [3] shows that one way to resolve the optimal amount of consumption vs. investment conflict is through an efficient rental market that allows people to trade their excess consumption flows of housing. The underlying assumption is that a transformation coefficient exists ( $\varphi 2$ in our model) that allows one to standardize consumption and rental flows. Geltner argues, however, that part of the consumption benefit of housing ownership requires ownership per se. Consequently, owner and rental housing should be treated as separate assets. Although the present paper finesses many problems with the assumption of no taxes, a previous version of this paper incorporated taxes because the tax treatment of owner-occupied housing is an important characteristic of the asset and helps to delineate owner and rental housing. We found that taxes exacerbated the market segmentation phenomenon. Taxes were taken out of the final version of the model to reduce its complexity. ${ }^{3}$ Glenn [11] argues that segmentation could also arise domestically on an intra-asset basis since institutional investors are constrained to hold only investment grade bonds and stocks. However, Hamada shows that this is a weak constraint because it assumes that a fixed supply exists and suggests that a mildly segmented structure is more appropriate for real estate vs. stocks because the supply of real estate is relatively inelastic over the short run.
} 
in the form of rental opportunity costs. ${ }^{4}$ Institutional investors thus restrict themselves to the securities market and income-producing properties.

The long production process necessary to manufacture real estate coupled with a rent-up period that further delays making a property fully operational also distinguishes real estate from other assets. This long process implies that the "instantaneous supply" argument that Black and Scholes [2] use to argue against a dividend effect is inappropriate for real estate.

Real estate also differs from stocks in that no short sales are allowed on direct real estate investment or on real estate securities such as CREFs that do not trade on an organized exchange. Investors however can short real estate securities that trade on the stock exchange such as REITs.

\section{Brief Literature Review}

The development of a pricing paradigm for real estate proceeds using prior modifications to the CAPM as an initial point of departure. Among prior CAPM modifications whose features are included in the present model are the Errunza and Losq [9] variation for the existence of a mildly segmented market structure and the Bosch [3] adjustment that recognizes not only the potential of durable assets for delivering services but also the existence of a rental market where these services can be traded. However, neither CAPM modification considers the impact of illiquidity on dividends. The Errunza and Losq version of the CAPM also does not recognize that some assets such as owner-occupied houses are not only an investment but also provide housing services that an owner can consume and that affects the pricing of all assets. ${ }^{5}$

The current model in contrast to Bosch [3] does not assume that rental costs are stochastic for purposes of tractability. Rental costs are assumed to be known and that net operating income (gross rents minus vacancy, operating expenses, and property taxes) is certain. ${ }^{6}$ The current model

\footnotetext{
${ }^{4}$ One could argue that segmentation doesn't exist in real estate markets because institutional investors invest in multifamily rental properties. However, this argument is valid only if the apartment returns are perfectly correlated with the return on single-family homes. In this extreme case, the super risk premium vanishes. ${ }^{5}$ Grossman and Laroque [12] in contrast to Bosch [3] incorporate illiquidity in the pricing of durable assets. Illiquidity is modelled as a proportionate transaction cost that impacts on the total return rather than only the price appreciation component of return. However, Grossman and Laroque assume that owners cannot trade off excess consumption of service flows because no rental market is assumed to exist.

${ }^{6}$ This is analogous to the assumption that Brennan [4] makes with respect to dividends. The assumption that NOI is certain is not unreasonable because a common type of lease arrangement in real estate is the triple net lease. The tenant under a triple net lease is responsible for insurance, utilities, and all operating expenses inclusive of property taxes.
} 
complements that of Geltner [10] who offers an alternative paradigm for pricing income-producing real estate but not owner-occupied housing within a CAPM framework. ${ }^{7}$

\section{Development of a Theoretical Real Estate Pricing Model}

\section{Introduction}

An equilibrium real estate pricing paradigm is developed in this section with respect to a mildly segmented market environment. The development of this model proceeds from relaxing some of the following assumptions which underlie the traditional CAPM: (A.I) Investors are mean-variance utility maximizers, (A.2) Every investor has the same opportunity set, (A.3) All investors have homogeneous expectations regarding means, variances, and covariances of returns. These asset returns have a joint normal distribution, (A.4) All investors define the relevant investment horizon in an identical fashion, (A.5) Perfect competition exists in the marketplace, (A.6) A risk-free asset exists. Investors can borrow and lend unlimited amounts at the riskless rate, (A.7) Information is costless and available to all investors simultaneously, (A.8) All assets are perfectly divisible, (A.9) All assets are fully marketable, (A. 10) Unlimited short sales are allowed, (A. 11) There are no transaction costs, and (A. 12) Taxes are nonexistent.

The present analysis maintains assumptions (A.I), (A.3)-(A.6), and (A.12). ${ }^{8}$ On the other hand, assumptions (A.2) and (A.7)-(A.11) are modified to recognize the unique characteristics associated with real estate. Following are the modified assumptions:

(A.2*) Two sets of investors $\Omega_{1}$ and ${ }_{2}$ exist. These investors have different opportunity sets because $\Omega_{1}$ investors are unable to invest in owner-occupied houses. Institutional investors and individual investors typify the $\Omega_{1}$ and $\Omega_{2}$ groups respectively. A mildly segmented housing market is present because $Q^{\wedge}$ investors are restricted to holding financial assets and income-producing real estate while $\Omega_{2}$ investors are unrestricted, i.e., all assets are eligible.

$\left(A .7^{*}\right)$ Information is available to all investors on all assets. However, capital market information is costless, while real estate information is costly.

\footnotetext{
${ }^{7}$ Geltner applies the consumption CAPM (CCAPM) of Breeden [1979] accounting for smoothing in the appraisalbased returns. The CCAPM ignores market imperfections but allows for a multiperiod investment horizon.

${ }^{8}$ Assumption (A.I) suggests that the physical attributes are mapped into mean-variance space. Assumption (A.3) implicitly presumes that both the buyer and seller of real estate use a fully informed agent(s). However, the agent is assumed to charge a large commission given the human capital required to gather information in a market with high information costs (see A.7*). Assumption (A.4) implies a one-period world. Assumption (A.5) implies that everyone is a price taker with more than one buyer assumed to exist for each property. However, the seller or his agent must incur time and costs in searching for buyers.
} 
$($ A.8*) Three asset submarkets exist-the market for financial assets, the income-producing real estate submarket inclusive of apartments, and the market for owner-occupied houses. Only equity securities and riskless debt trade in the financial market with all financial assets perfectly divisible. No property trades in both the income-producing real estate and owner-occupied housing market. Properties trading in either real estate submarkets are not divisible. However, real estate funds that are perfectly divisible exist for both real estate submarkets. Each property is associated with a real estate fund. Two types of real estate funds are present. The first fund type trades as a security in the financial market and is fully marketable with short sales allowed, e.g., equity real estate investment trusts. The second type of fund is illiquid and does not trade on an organized exchange.

(A.9*) Financial assets are fully marketable. However, illiquidity exists for real estate except REITs but only affects the resale component of return with the net income component assumed to be certain and known at the beginning of the period. The degree of liquidity might differ between the incomeproducing real estate and the owner-occupied housing markets but is assumed identical among properties trading within a real estate submarket.

(A. 10*) Unlimited short sales are allowed for securities including real estate stocks such as REITs. However, no short sales are permitted for the underlying real estate or for real estate funds that do not trade in the capital market.

(A.11*) Transaction costs exist for all assets and include costs that investors incur to obtain information from agents. Transaction costs for financial assets are stated on a per share basis with the investor charged a commission both when he buys and subsequently sells a financial asset. In contrast, a real estate owner pays a transaction cost only when the property is sold and this cost is stated as a percentage of the final sales price. The transaction cost for real estate is modelled as part of a more general liquidity cost.

In addition to these assumptions, the subsequent analysis assumes that the rental market for housing is efficient and in equilibrium. This rental market allows an owner to trade service (consumption) flows associated with owner-occupied housing.

\section{Notation and Definitions}

The subscript $i$ refers to the $i$ th investor with $\Omega_{1}$ and $\Omega_{2}$ denoting the first and second set investors respectively, and $\Omega$ denotes the set of all investors. Each investor is assumed to possess an implicit utility function of the form $U\left\{G_{i}, E_{i}, V_{i}\right)$ for $i \in \Omega_{1}$ and $U\left(C_{i}, G_{i j} E_{i}, V_{i}\right)$ for $i \in \Omega_{2}$ where $C_{i}$ is the $i$ th individual's consumption of services derived from occupying a house, $G$; is individual f's consumption of all other goods that do not possess any investment features, and $E_{i}$ and $V_{i}$ are the expected terminal wealth and its variance respectively for the ith individual. Individual $i$ 's utility is assumed to increase in a nonnegative manner with respect to all arguments of the utility function except for risk i.e. $\partial U \mid \partial C \geq 0$, $\partial U|\partial G \geq 0, \partial U| \partial E \geq 0$, and $\partial U \mid \partial V \geq 0$. 
Subscript $j$ stands for the $j$ th asset. The $j$ th asset can trade in either the security market $S$, the market for income-producing real estate $l$, or the owner-occupied housing market $H$. Boldfacing signifies a vector, the tilde ( $\sim$ ) denotes randomness, while the prime (') is the transposition operator. The expectations operator is $E$ and $r$ represents the unity vector. Subscript $f$ denotes the investment in the riskless bond $b$. Capital letter $\mathrm{X}$ stands for the vector containing the dollar amounts invested in assets with the subscript indicating the type of asset. The capital letter $R$ represents the rate of return before taxes. The rate-of-return $R$ consists of two components-the resale component $\left(\pi=\left[\left(\frac{P_{1}}{P_{0}}\right)-1\right]\right)$ and the income component ( $d$ ). The letter $d$ denotes the net income yield for real estate, which is defined as gross rental income less vacancy, operating expenses, and property taxes stated as a proportion of the original price $P_{0}$. On the other hand, $\gamma$ represents the net imputed rent that arises if a property owner decides to consume a portion or all of the housing services associated with owner-occupied houses. Both the net income yield for real estate and the dividend yield for stock are assumed to be known at the beginning of the period. Separation of the return into two components is necessary because the proportionate cost of liquidity $(L)$ for real estate is only associated with capital gains. The symbol $\phi$ stands for transaction costs, which is additive for stocks because transaction costs for stocks are stated as a price per share. Transaction costs for real estate are included in the proportionate cost of liquidity, i.e., $L_{I}=f\left(\phi_{l}\right)$ and $L_{H}=f\left(\phi_{H}\right)$ where $L$ is stated as a percentage of the capital gain and $L, \phi \in[0,1)$. Transaction costs are assumed to be zero for riskless bonds.

The return vector $R$, the dollar investment vector $X$, the variance- covariance matrix $C$ and the vector of aggregate market values $P$ are partitioned according to asset markets in a fashion similar to Errunza and Losq [9] as follows:

$$
\begin{aligned}
& \tilde{\mathbf{R}} \equiv\left[\tilde{\mathbf{R}}_{S} \tilde{\mathbf{R}}_{I} \tilde{\mathbf{R}}_{H}\right]^{\prime} \quad \mathbf{X} \equiv\left[\mathbf{X}_{S_{l}} \mathbf{X}_{I_{l}} \mathbf{X}_{H_{l}}\right]^{\prime} \quad \mathbf{P} \equiv\left[\mathbf{P}_{S} \mathbf{P}_{I} \mathbf{P}_{H}\right]^{\prime} \\
& \mathbf{C} \equiv\left[\begin{array}{ccc}
\mathbf{C}_{S S} & \left(1-L_{I}\right) \mathbf{C}_{S I} & \left(1-L_{H}\right) \mathbf{C}_{S H} \\
\left(1-L_{I}\right) \mathbf{C}_{I S} & \left(1-L_{I} \mathbf{C}_{I I}\right. & \left(1-L_{I}\right)\left(1-L_{H}\right) \mathbf{C}_{I H} \\
\left(1-L_{H}\right) \mathbf{C}_{H S} & \left(1-L_{I}\right)\left(1-L_{H}\right) \mathbf{C}_{H I} & \left(1-L_{H}\right)^{2} \mathbf{C}_{H H}
\end{array}\right]
\end{aligned}
$$

Explicit recognition of asset submarkets necessitates the introduction of three asset market portfolios:

(1) The Security Market Portfolio (MPS) where MPS $=\left[\mathrm{P}_{S} 00\right]^{\prime}$. This MPS portfolio has market value $M_{S}$ and rate return $\widetilde{R}_{M_{S^{\prime}}}(2)$ The Income-Producing Submarket I Portfolio (MPI) where MPI=[OP,0]'. This MPI portfolio has market value $M_{I}$ and rate of return $\tilde{R}_{M_{I}}$, and (3) The Owner Occupied Housing Submarket $H$ Portfolio $(\mathrm{MPH})$ where $\mathrm{MPH}=\left[00 \mathrm{P}_{H}\right]^{\prime}$. This $\mathrm{MPH}$ portfolio has market value $M_{H}$ and rate of return $\tilde{R}_{M_{H}}$. 
These three portfolios represent the components from decomposing the market portfolio MP where MP $=P=M P S+M P I+M P H$.

The Greek letter $\theta$ is a segmentation parameter that reflects the extent to which the owneroccupied housing market is segmented from the markets for financial assets and the income-producing real estate where $1>\theta>0$ if the housing market is mildly segmented and $\theta=1$ if all markets are integrated. The Greek letters $\lambda_{1}$ and $\lambda_{2}$ represent the absolute risk-aversion coefficient for the $\Omega_{1}$ and $\Omega_{2}$ investors respectively, while the market risk-aversion coefficient for the aggregate population of investors is $\lambda$ where $\lambda^{-1}=\lambda_{1}{ }^{-1}+\lambda_{2}^{-1}$ and $\lambda, \lambda_{1}, \lambda_{2}>0$ by assumption of risk-aversion with

$\lambda_{1}=\left[\sum_{i \in \Omega_{1}}\left(U_{E_{i}} \div U_{V_{i}}\right)\right]^{-1}$

and

$$
\lambda_{2}=\left[\sum_{i \in \Omega_{2}}\left(U_{E_{i}} \div U_{V_{i}}\right)\right]^{-1}
$$

and $U_{E_{i}}=\partial U \mid \partial E_{i}$. And $U_{V_{i}}=\partial U \mid \partial V_{i}$.

The aggregate marginal rate of substitution of the expected return for the consumption of housing services for $\Omega_{2}$ investors is $\varphi_{2}$.

In addition to the preceding notation, we shall use the following definitions from Errunza and Losq [9] modified to suit our situation:

Definition 1: The conditional market risk of an asset is defined as the conditional covariance of its return relative to the return on an asset market portfolio with the returns on all other assets held constant. Given a multivariate normal distribution, the conditional covariance does not depend on the asset returns held constant.

Definition 2: $\mathrm{DP}_{\mathrm{HI}}=\left[\mathrm{C}_{\mathrm{SSI}}^{-1} \mathrm{C}_{\mathrm{SHI}} \mathrm{P}_{\mathrm{H}} 00\right]^{\prime}$ is a diversified portfolio of capital market securities that is most highly correlated with the portfolio $\mathrm{MPH}$ after factoring out any income-producing real estate submarket $(I)$ influence. $\mathrm{DP}_{\mathrm{HS}}=\left[0 \mathrm{C}_{\mathrm{HS}}^{-1} \mathrm{C}_{\mathrm{IHS}} \mathrm{P}_{\mathrm{H}} 0\right]^{\prime}$ is a diversified portfolio of income properties trading in real estate submarket $I$, which is most highly correlated with the portfolio MPH after holding the impact of the security market constant.

Definition 3: $\mathrm{HP}_{\mathrm{H} \cdot \mathrm{I}}=\mathrm{MPH}-\left(1-\mathrm{L}_{\mathrm{H}}\right) \mathrm{DP}_{\mathrm{H} \cdot \mathrm{I}}$ is a conditional hedge portfolio consisting of a long position in the housing submarket portfolio MPH and a short position in the diversified portfolio $\mathrm{DP}_{\mathrm{H} \cdot \mathrm{I}}$. Proofs of these definitions are verifiable using the theorems in either Anderson [1, p. 30-34] or Dhrymes [7, Theorem 2, p. 24]. 
The Model

Relaxation of the CAPM assumptions leads to the proposition that if the investment markets for all assets are in equilibrium and the rental market for owner-occupied housing is efficient and in equilibrium then: ${ }^{9}$

(1.1) The marginal rate of substitution between the consumption of housing services and the expected return to owner-occupied housing is equal to the ratio of the net imputed rent from owner occupancy to the cash How from renting out the house. In other words, the net income yield from renting out an owned unit is equal to the opportunity cost of the housing services.

$\left(\gamma_{H_{j}} / d_{H_{j}}\right)=\left(\partial C_{i} / \partial E_{i}\right)=\left(1 / \varphi_{2}\right)$

(1.2) The equilibrium price for stocky is

(2)

$E\left(\widetilde{R}_{S_{j}}-r_{f}\right)=\left(2+r_{f}\right) \phi_{S}+\theta\left[E\left(\widetilde{R}_{M^{*}}-r_{f}\right)+\psi\right] \beta_{S_{j}}^{\dagger}$

(1.3) The equilibrium price for the $j$ th income-producing real estate is

(3)

$E\left(\tilde{R}_{I_{j}}-r_{f}\right)=\left(\frac{L_{I}}{1-L_{I}}\right)-\left(\frac{L_{I}}{1-L_{I}}\right)\left(d_{I_{j}}-r_{f}\right)+\theta\left[E\left(\tilde{R}_{M^{*}}-r_{f}\right)+\psi\right] \beta_{I_{j}}^{\dagger}$

(1.4) The equilibrium price for the $j$ th owner-occupied house is

(4)

$E\left(\tilde{R}_{H_{j}}-r_{f}\right)=\left(\frac{L_{H}}{1-L_{H}}\right)-\left(\frac{L_{H}}{1-L_{H}}\right)\left(\varphi_{2} \gamma_{H_{j}}-r_{f}\right)+\theta\left[E\left(\tilde{R}_{M^{*}}-r_{f}\right)+\psi\right] \beta_{H_{j}}^{\dagger}+(1-\theta)\left(\frac{1}{1-L_{H}}\right)\left[E\left(\tilde{R}_{M^{*}}-r_{f}\right)+\psi\right] \beta_{H_{j} \mid S I}^{\dagger}$

(1.5) The aggregate portfolio demand for the $\Omega_{1}$ and $\Omega_{2}$ set of investors respectively are

(5)

$\mathrm{X}_{\Omega_{1}}=\left(\frac{\lambda}{\lambda_{1}}\right)\left\{\mathbf{M P S}+\left(1-L_{H}\right) \mathbf{D} \mathbf{P}_{H \cdot I}+\mathbf{M P I}+\left(\frac{1-L_{H}}{1-L_{I}}\right) \mathbf{D P} \mathbf{P}_{H \cdot S}\right\}$

\footnotetext{
${ }^{9}$ If the rental market for owner-occupied houses is not in equilibrium, then similar results except that the term $d_{H_{I}}$ replaces $\varphi_{2} \gamma_{H_{I}}$ the pricing of houses and the $\psi$ term in the risk premium is replaced with $\Lambda$ where $\Lambda=L_{f}\left(M_{l} / M^{*}\right)\left(d_{M_{i}}-r_{f}\right)+L_{H^{\prime}}\left(M_{H^{\prime}} / M^{*}\right)\left(d_{M_{n}}-r_{f}\right)-\sum_{j \in B} L_{j}\left(M_{j} / M^{\star}\right)-\left(2+r_{f}\right)\left(M_{S} / M^{*}\right) \phi_{S}$

In other words, the risk premium does not depend on the aggregate consumption of housing services if the rental market for housing is not in equilibrium.
} 
(6)

$\mathrm{X}_{\Omega_{2}}=\left(\frac{\lambda}{\lambda_{1}}\right) \mathbf{M P}+\left(\frac{\lambda_{2}-\lambda}{\lambda_{2}}\right) \mathbf{H} \mathbf{P}_{H \cdot I}-\left(\frac{\lambda_{2}-\lambda}{\lambda_{2}}\right)\left(\frac{1-L_{H}}{1-L_{I}}\right) \mathbf{D} \mathbf{P}_{H \cdot S}$

where $M^{*}=M_{S}+\left(1-L_{1}\right) M_{I}+\left(1-L_{H}\right) M_{H}=M_{S}+M_{I}^{*}+M_{H}^{*}$ is the aggregate value of the modified market portfolio after adjusting for illiquidity associated with real estate, $\widetilde{R}_{M^{*}}=\left(\frac{M_{S}}{M^{*}}\right) \widetilde{R}_{M_{S}}+\left(\frac{M_{I}^{*}}{M^{*}}\right) \widetilde{R}_{M_{I}}+$ $\left(\frac{M_{H}^{*}}{M^{*}}\right) \widetilde{R}_{M_{H}}$ is the return on the modified market portfolio, $\beta_{j}^{\dagger}$ is the measure of systematic risk for asset $j$ and $\beta_{H_{j} / S I}^{\dagger}$ is the conditional risk measure associated with the owner-occupied housing market which is defined as

(7)

$\beta_{j}^{\dagger}=\left[\frac{\operatorname{cov}\left(\tilde{R}_{j}, \tilde{R}_{M^{*}}\right)}{\operatorname{var}\left(\tilde{R}_{M^{*}}\right)}\right]$ and $\beta_{H_{j} \mid S I}^{\dagger}=\left[\frac{\operatorname{cov}\left(\tilde{R}_{j}, R_{M_{H}} \mid \tilde{R}_{S}, \tilde{R}_{I}\right)}{\operatorname{var}\left(\tilde{R}_{M_{H}} \mid \tilde{R}_{S}, \tilde{R}_{I}\right)}\right]$,

and $\psi$ represents an adjustment to the excess return on the market portfolio $E\left(\tilde{R}_{M_{*}}-r_{f}\right)$. The term $\psi$ recognizes the aggregate excess income yield on the portfolios $I$ and $H$ and the aggregate transaction and illiquidity costs associated with the market portfolio and is defined as follows:

(8)

$$
\begin{aligned}
& \psi=L_{I}\left(M_{I} / M^{*}\right)\left(d_{M_{I}}-r_{f}\right)+L_{H}\left(M_{H} / M^{*}\right)\left(\varphi_{2} \gamma_{H}-r_{f}\right) \\
& -\sum_{j \in B} L_{j}\left(M_{j} / M^{*}\right)-\left(2+r_{f}\right)\left(M_{S} / M^{*}\right) \phi_{S}
\end{aligned}
$$

The proposition is proven in the appendix.

\section{Results ad Implications of the Model}

Several new findings arise when the CAPM assumptions are relaxed to recognize the unique features of real estate and the markets within which it trades in addition to other results that are consistent with prior CAPM modifications. One distinctive feature of this study is that a separate pricing paradigm corresponds to financial assets, income-producing real estate and owner-occupied housing, respectively, with the prices of all assets fully reflecting the opportunity costs of the consumption flows that owner-occupied houses generate. Another distinctive feature is that both the marginal rate of substitution (MRS) between expected return and risk and the MRS between consumption and risk influence the equilibrium price for owner-occupied housing. The MRS between expected return and consumption also influences the equilibrium price for owner-occupied housing through the $\varphi_{2}$ term. 
The component of the opportunity cost of housing services that is tradable and accrues in a portfolio context enters into the pricing of all assets through the $\psi$ term in the risk premium $\theta\left[E\left(\tilde{R}_{M *}-\right.\right.$ $\left.r_{f}\right)+\psi$ ]. For owner-occupied houses, the opportunity cost of housing services also enters into the pricing through the excess "dividend" effect because the opportunity cost of housing services is equal to the cash flow that accrues to the owner if the home is rented out. This finding is consistent with the implications of Bosch [3].

The valuation model for financial assets, income-producing real estate and owner-occupied houses are similar in that beta is still the measure of systemic risk as in the traditional CAPM but now beta is measured with respect to the market portfolio $M^{*} . M^{*}$ differs from the traditional CAPM market portfolio in that $M^{*}$ explicitly recognizes that the aggregate amounts invested in income-producing real estate $M_{I}^{*}$ and owner-occupied houses $M_{H}^{*}$ are subject to illiquidity. Further, an additional measure of risk is associated with properties that trade in the owner-occupied housing submarket. This conditional risk measure arises because a mildly segmented housing market exists. In other words, because the demand for houses is restricted, it makes sense that housing prices should be lower, which leads to an additional return premium. These findings are consistent with the results of Errunza and Losq [9].

Although beta is still the measure of systematic risk, the risk premium associated with beta is different from the traditional CAPM premium. The risk premium $\theta\left[E\left(\tilde{R}_{M *}-r_{f}\right)+\psi\right]$ represents an extension of the risk premium in the standard CAPM because the excess return on the redefined market portfolio is adjusted downward for an aggregate dividend effect that arises from an asymmetrical liquidity structure and is also adjusted downward for the impact of aggregate transaction costs for stocks.

The parameter $\theta$ adjusts the risk premium to reflect the extent to which the owner-occupied housing market is mildly segmented from the stock market and the income-producing real estate market. Alternatively, $\theta$ represents a continuous segmentation parameter that is equal to one if markets are integrated and is between zero and one if asset markets are mildly segmented. The owner-occupied housing market becomes more integrated with other asset markets $(\theta \rightarrow 1)$ if institutional investors $\left(\Omega_{1}\right)$ are successful in constructing a surrogate portfolio for owner-occupied houses comprised of stocks, such as REITs, and property types, such as apartments, whose returns exhibit a high correlation with the return on the portfolio of owner-occupied houses. In the extreme, if the returns of these two portfolios are perfectly correlated, then all investors hold the market portfolio MP and act as if a completely integrated market structure prevails. The magnitude of the risk premium for systematic risk is therefore 
not invariant to whether a mildly segmented or integrated market structure exists. ${ }^{10}$ The risk premium given mildly segmented markets is a proportion $\theta$ of the risk premium if integrated markets obtain. The super risk premium that arises from owning a house is also a function of this segmentation parameter. This super risk premium decreases the more integrated markets become or the more successful $\Omega_{1}$ investors are in "spanning" the markets by investing in assets whose returns exhibit a high correlation with the return on owner-occupied houses. The magnitude of the super risk premium for housing also varies in direct proportion with the degree to which an owner-occupied home is illiquid. The more illiquid an owner-occupied home is, the higher is the super risk premium associated with that home.

A "dividend effect" corresponds to real estate but not stocks because only the former is subject to illiquidity. In contrast to stocks, an investor in real estate is usually unable to make a quick sale at full market value. Thus, illiquidity is associated with the appreciation component but not the income component of real estate returns. Investors therefore bid up the price of real estate the higher the income yield, ceteris paribus. Alternatively, investors are willing to accept a lower return the higher the expected income yield. ${ }^{11}$

Although a separate pricing paradigm corresponds to financial assets, income-producing real estate, and owner-occupied housing respectively, all three asset models collapse to the traditional CAPM when no imperfections exist. The traditional CAPM thus represents a special case of each model.

The optimal portfolios that $\Omega_{1}$ and $\Omega_{2}$ investors hold are consistent with the findings of previous segmentation studies. The separation principle still holds with respect to a mildly segmented market structure because the relative holdings of securities and real estate for $\Omega_{1}$ and $\Omega_{2}$ investors are independent of their preferences. Separation also obtains between the optimal amount to consume and the optimal amount to invest in owner-occupied housing if an efficient rental market exists for housing. In addition to this, institutional investors who are restricted from holding owner-occupied houses will construct a surrogate portfolio(s) that proxies for this asset class. This implies that investors in $\Omega_{1}$ will tilt their portfolio of financial assets toward securities whose returns are highly correlated with the equity return on the submarket portfolio of owner-occupied houses after factoring out any income-producing real estate market influence. This diversified portfolio of financial securities is denoted $\mathrm{DP}_{\mathrm{H}^{*} \cdot}$

\footnotetext{
${ }^{10}$ Our results contrast with Errunza and Losq (E-L) because the E-L model implies that assets eligible to all investors are priced as if an integrated market obtains and also that the risk premium for all eligible assets is invariant to which market structure exists.

${ }^{11}$ This conclusion holds in a one-period world without taxes. However, if income returns are taxed at a different rate than appreciation returns or if both types of returns are taxed at the same rate but a multiperiod context is used, then a tradeoff will exist between the dividend effect due to illiquidity that is noted here and the traditional dividend effect due to tax clienteles of Brennan [4].
} 
Institutional investors will also tilt their portfolio of income-producing properties towards those properties that exhibit the highest correlation to the owner-occupied housing market, holding constant the impact of the securities market $\left(D P_{H \cdot 1}\right)$.

Conditional correlations rather than first-order correlations are used in the portfolio formation process because restricted investors $\left(\Omega_{1}\right)$ can use either financial assets or income-producing properties to construct a substitute portfolio for owner-occupied housing. This use of conditional covariances is absent in the portfolio formation process of all other segmentation studies. The focus on conditional covariances implicitly suggests that certain factors such as inflation and interest rates may he driving returns on all assets. As such, the use of conditional covariances factors out common influences and focuses on incremental diversification benefits. The tilting of portfolios for restricted investors allows these investors to participate indirectly in owner-occupied housing. Unrestricted investors $\left(\Omega_{2}\right)$ in contrast to restricted investors can short the surrogate housing market portfolio that consists of financial assets $\mathrm{DP}_{\mathrm{H} \cdot \mathrm{l}}$ because they are constrained to hold all of the equity in the owner-occupied housing $(\mathrm{MPH})$. Shorting $\mathrm{DP}_{\mathrm{H} \cdot \mathrm{l}}$ allows unrestricted investors to imperfectly arbitrage away a portion of the super risk premium. Unrestricted investors also tilt the market portfolio of income-producing real estate away from properties that exhibit a high correlation with the owner-occupied housing submarket portfolio MPH. However, no short sales are allowed on the diversified portfolio $\mathrm{DP}_{\mathrm{H} \cdot \mathrm{l}}$ in contrast to portfolio $\mathrm{DP}_{\mathrm{H} \cdot \mathrm{l}}$ because this surrogate consists of income-producing real estate. The implication is that individual (unrestricted) investors should not invest heavily in apartments or apartment REITs hut should invest instead in nonresidential income-producing properties if the returns on apartments are highly correlated with the returns on owner-occupied houses. In summary, both restricted and unrestricted investors tend to tilt their respective portfolios away from the traditional CAPM's overall market portfolio of risky assets.

The extent to which restricted (unrestricted) investors invest (short) in the surrogate portfolio of the owner-occupied housing market is a function of the absolute risk aversion of restricted investors relative to unrestricted investors, the correlation of the returns on the surrogate portfolio of housing to the return on the actual housing market portfolio, and the proportionate cost of illiquidity associated with residential and income-producing real estate. Following is a discussion of the impact of each factor on optimal investor portfolios.

Factor 1: Absolute Risk Aversion of Restricted Investors Relative to Unrestricted Investors. Restricted investors reduce their holdings of all assets as they become more risk averse relative to unrestricted investors. In the limit, unrestricted investors do not construct either a hedge portfolio or tilt the income- 
producing real estate market portfolio $\mathrm{MPI}$ in the amount $\mathrm{DP}_{\mathrm{H} \cdot \mathrm{s}}$ because the super risk premium is negligible in this instance.

Factor 2: Correlation of $\mathrm{DP}_{\mathrm{H} \cdot \mathrm{S}}$ and $\mathrm{DP}_{\mathrm{H} \cdot \mathrm{l}}$ respectively with the Housing Market Portfolio MPH. If either of the conditional surrogate portfolios for the housing submarket ( $D P_{H \cdot I}$ or $D_{\mathrm{H} \cdot \mathrm{S}}$ ) is perfectly correlated with the housing market portfolio $\mathrm{MPH}$, then all investors act as if a completely integrated market structure prevails.

Factor 3: The Proportionate Cost of Liquidity. Restricted investors $\left(\Omega_{1}\right)$ reduce their long positions in the two surrogate housing market portfolios as the proportionate illiquidity cost increases for owneroccupied houses. Unrestricted investors also reduce their short position in $\mathrm{DP}_{\mathrm{H}^{\cdot} \cdot \mathrm{l}}$ and tilt their portfolio away from income-producing real estate whose returns are highly correlated with owner-occupied houses. The reduction in holding the diversified portfolio of income-producing real estate $\mathrm{DP}_{\mathrm{H} \cdot \mathrm{S}}$ is offset however as the proportionate cost of illiquidity increases for income- producing real estate relative to that for owner-occupied houses.

\section{Summary and Conclusions}

Relaxation of the CAPM assumptions to recognize the features of real estate and the markets within which it trades leads to several new findings. Among these is that a separate valuation model is associated with each asset class. This suggests that systematic mispricing of real estate will occur if the pricing model for financial assets is applied to real estate. Real estate mispricing occurs in part because of illiquidity, which leads to both an illiquidity premium and a dividend effect for real estate. The dividend effect suggests that investors will hid up the price of property that exhibits a higher income yield, ceteris paribus. Although beta is still the measure of systematic risk, the magnitude of the risk premium associated with beta is not invariant to whether a mildly segmented or integrated market structure exists and is a function of the degree to which asset markets are segmented. Another finding is that the consumption of housing services impacts on the pricing of all assets if the rental market for housing is in equilibrium and is efficient. The study also shows that investors who are restricted from investing in owner-occupied housing use either financial assets or income-producing real estate that exhibit a high correlation with returns on owner-occupied housing to construct a surrogate housing market portfolio. Unrestricted investors also construct a surrogate housing market portfolio to imperfectly hedge housing market risk. The extent to which either set of investors uses this surrogate portfolio depends not only on the degree of risk aversion but also on illiquidity.

Several future avenues of research arise from this study. These include extending the present model to account for holding period clienteles, taxes, or leverage in either a single period or multiperiod context and assessing the impact of these imperfections on the illiquidity premium. In a multiperiod world, the illiquidity premium will be mitigated by the possibility of long holding periods that result in 
holding period clienteles. Further, the dividend effect due to illiquidity is partially offset in a world of asymmetrical taxes or a multiperiod world with symmetrical taxes. In addition to this, the possibility of borrowing against real estate equity should reduce the illiquidity premium in a more complete general equilibrium model.

\section{Appendix}

In this appendix, we derive equation (1) through equation (6) on pages 9-10. However, we shall introduce the following notation prior to deriving the theoretical model.

\section{Notation in Proof}

$\mathrm{S}, \mathrm{I}, \mathrm{H}=$ financial assets, income-producing real estate, and owner-occupied houses respectively $X_{S_{i}}, X_{I_{i}}, X_{H_{i}}=$ asset vectors of portfolio holdings for the ith investor

$X_{H_{i}}^{C}=$ quantity of owner-occupied housing that the ith investor consumes

$X_{H_{i}}^{R}=X_{H_{i}}-X_{H_{i}}^{C}$; housing units rented to or from others for additional income and consumption $X_{f_{i}}==$ dollar amount that investor $i$ invests in the risk-free asset

$X_{R_{i}}=\left[X_{S_{i}} X_{I_{i}}\right]^{\prime} ; X_{U_{i}}=\left[X_{S_{i}} X_{I_{i}} X_{H_{i}}\right]^{\prime}$

$E_{S}\left[E\left(\tilde{\pi}_{S}+d_{S}-\Phi_{S}\right)-\left(i+\Phi_{S}\right) R_{f}\right]$; mean end of period wealth vector for financial securities

$E_{I}=\left[E\left(\tilde{\pi}_{I}\right)\left(1-L_{I}\right)+d_{I}-i R_{f}\right] ;$ mean end of period wealth vector of income-producing real estate

$E_{H}=\left[E\left(\tilde{\pi}_{H}\right)\left(1-L_{H}\right)-i R_{f}\right]$; mean end of period wealth appreciation vector of owner-occupied houses

$E_{H}^{R}=\left[d_{H}\right]$; income component of owner-occupied houses

$E_{R}=\left[E_{S} E_{I}\right]^{\prime} ; E_{U}=\left[E_{S} E_{I} E_{H}\right]^{\prime} ;\left[E=E_{S} E_{I} E_{H}+E_{H}^{R}\right]^{\prime} ; E_{U}^{*}=\left[\left[E_{S} E_{I}\right] E_{H}\right]^{\prime}$

$U_{G_{i}}=\left(\frac{\partial U_{i}}{\partial G_{i}}\right) U_{E_{i}}=\left(\frac{\partial U_{i}}{\partial E_{i}}\right) U_{V_{i}}=\left(\frac{\partial U_{i}}{\partial V_{i}}\right) U_{C_{i}}=\left(\frac{\partial U_{i}}{\partial C_{i}}\right) ;$ marginal utilities

$\gamma_{H_{j}}=$ net imputed rent for owner-occupied housing; $\Gamma_{H}=\left[00 \gamma_{H}\right]^{\prime}$

$\sum_{R}\left[\begin{array}{llll}a_{11} & C_{S S} & a_{12} & C_{S I} \\ a_{21} & C_{I S} & a_{22} & C_{I I}\end{array}\right]$ 


$$
\begin{aligned}
& \xi_{U}\left[\begin{array}{llllll}
a_{11} & C_{S S} & a_{12} & C_{S I} & a_{13} & C_{S H} \\
a_{21} & C_{I S} & a_{22} & C_{I I} & a_{23} & C_{I H} \\
a_{31} & C_{H S} & a_{32} & C_{H I} & a_{33} & C_{H H}
\end{array}\right] \\
& a_{11}=1, a_{12}=a_{21}=\left(1-L_{I}\right), a_{22}=a_{21}^{2}, a_{13}=a_{31}=\left(1-L_{H}\right), a_{23}=a_{32} \\
& =\left(1-L_{I}\right)\left(1-L_{H}\right) \text {, and } a_{33}=a_{13}^{2}
\end{aligned}
$$

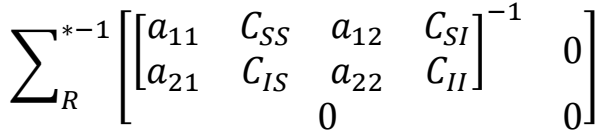

$$
\begin{aligned}
& \sum_{A}=\left[\begin{array}{llllll}
a_{11} & C_{S S} & a_{12} & C_{S I} & a_{13} & C_{S H} \\
a_{21} & C_{I S} & a_{22} & C_{I I} & a_{23} & C_{I H}
\end{array}\right] \\
& \sum_{B}=\left[a_{31} C_{H S} a_{32} C_{H I} a_{33} C_{H H}\right] ; \\
& \sum_{C}=\left[a_{31} C_{H S} a_{32} C_{H I}\right] ; \sum_{C}^{*}=\left[a_{13} C_{S H} a_{23} C_{I H}\right] \\
& \rho_{H \mid S I}=\left(M_{H} M_{H}^{*} / M^{*}\right) \operatorname{var}\left(\tilde{R}_{M_{H}} \mid \tilde{R}_{S}, \tilde{R}_{I}\right) ; \rho=M^{*} \operatorname{var}\left(\tilde{R}_{M^{*}}\right) \\
& P=\left[P_{S} P_{I} P_{H}\right]^{\prime}=\text { vector of aggregate market value for all assets; } \\
& P_{R}=\left[P_{S} P_{I}\right]^{\prime} \\
& w_{E V_{i}}=\left(-U_{E_{i}} / 2 U_{V_{i}}\right) ; \quad w_{C V_{i}}=\left(-U_{C_{i}} / 2 U_{V_{i}}\right) \\
& \zeta_{1}=\left[\sum_{i \in \Omega_{1}} w_{E V_{i}} / \sum_{i \in \Omega} w_{E V_{i}}\right] ; \zeta_{2}=\left[\sum_{i \in \Omega_{2}} w_{E V_{i}} / \sum_{i \in \Omega} w_{E V_{i}}\right] ; \varphi_{2}=\sum_{i \in \Omega_{2}} w_{C V_{i}} \div \sum_{i \in \Omega_{2}} w_{E V_{i}} \\
& h=\left(1 \div \sum_{i \in \Omega} w_{E V_{i}}\right) ; h_{2}=\left(1 \div \sum_{i \in \Omega_{2}} w_{E V_{i}}\right) ; \lambda^{-1}=\sum_{i \in \Omega} w_{E V_{i}} ; \lambda_{2}^{-1}=\sum_{i \in \Omega_{2}} w_{E V_{i}} \\
& \tilde{R}_{K_{j}}=\tilde{\pi}_{K_{j}}+d_{K_{j}}-1 K=S, I, H \text { and } R_{f}=\pi_{b_{j}} \text { with } r_{f}=\pi_{b_{j}}-1 \text {; return on the risk-free bond } \\
& \tilde{R}_{M *}=\left(M_{S} / M^{*}\right) \tilde{R}_{M_{S}}+\left(M *_{l} / M^{*}\right) \tilde{R}_{M_{l}}+\left(M_{H}^{*} / M^{*}\right) \widetilde{R}_{M_{H}} ; \text { return on } M^{*} \\
& M^{*}=M_{S}+\left(1-L_{I}\right) M_{I}+\left(1-L_{H}\right) M_{H}=M_{S}+M_{I}^{*}+M_{H}^{*} \\
& \text { Proof }
\end{aligned}
$$

Decision Problem for Any Restricted $\Omega_{1}$ Investor: The investment decision for investor $i \in \Omega_{1}$ is to maximize his expected utility with respect to $\left\{X_{S_{i}} X_{I_{i}}, G_{i}\right\}$ 
$1 \mathrm{~A}$

$\max U_{i}\left(G_{i}, E_{i}, V_{i}\right) \quad i \epsilon \Omega_{1}$

s.t. $W_{o_{i}}=\mathbf{X}_{f_{i}}+G_{i}+\mathbf{X}_{S_{i}^{\prime}}\left(l+\Phi_{S}\right)+\mathbf{X}_{I_{i}} l$ and $\mathbf{X}_{I_{i}} \geq 0$

where the mean end of period wealth $E_{i}$ and the variance of the end period wealth $V_{i}$ are $E_{i}=W_{o_{i}} R_{f}-G_{i} R_{f}+\mathbf{X}_{S_{i}} \mathbf{E}_{S}+\mathbf{X}_{I_{i}}{ }^{\prime} \mathbf{E}_{I}$ and $V_{i}=\mathbf{X}_{\mathrm{R}_{i}}{ }^{\prime}{ }_{{ }_{R}} \mathbf{X}_{R_{i}}$

The First Order Conditions (FOC) associated with this decision problem are

$2 A$

$w_{E V} \mathbf{E}_{R}=\sum_{R} \mathbf{X}_{R_{i}}$ and $U_{G_{i}}=U_{E_{i}} R_{f}$

Decision Problem for Any Unrestricted $\Omega_{2}$ Investor: The decision for investor $i \in \Omega_{2}$ is to

maximize his expected utility with respect to $\left\{X_{S_{i}}, X_{I_{i}}, X_{H_{i}}, X_{H_{i}}^{R}, G_{i}\right\}$ subject to a wealth constraint and no short sale restrictions on $X_{I_{i}}$ and $X_{H_{i}}$.

$3 A$

s.t. $W_{o_{i}}=\mathbf{X}_{f_{i}}+G_{i}+\mathbf{X}_{S_{i}}^{\prime}\left(l+\Phi_{S}\right)+\mathbf{X}_{I_{i}^{\prime}} l+\mathbf{X}_{H_{i}^{\prime}} l$ and $\mathbf{X}_{I_{i}} \geq 0, \mathbf{X}_{H_{i}} \geq \mathbf{0}$

where the amount of owner-occupied housing services investor $i$ consumes, and the mean variance of the end-of-period wealth respectively are

$C_{i}=\mathbf{X}_{H_{i}}^{C} \gamma_{H}=\left(\mathbf{X}_{H_{i}}-\mathbf{X}_{H_{i}}^{R}\right)^{\prime} \gamma_{H}$

$E_{i}=W_{o_{i}} R_{f}^{a}-G_{i} R_{f}^{a}+\mathbf{X}_{S_{i}^{\prime}}^{\prime} \mathbf{E}_{S}+\mathbf{X}_{I_{i}}^{\prime} \mathbf{E}_{1}+\mathbf{X}_{H_{i}}^{\prime} \mathbf{E}_{H}+\mathbf{X}_{H_{i}}^{R} \mathbf{E}_{H}^{R}$ and $V_{i}=\mathbf{X}_{U_{i}^{\prime}}^{\prime} \mathbf{X}_{U} \mathbf{X}_{U_{i}}$

The resulting first-order conditions are

$4 \mathrm{~A}$

$$
w_{C V_{i}} \Gamma_{H}+w_{E V_{i}} \mathbf{E}_{U}=\sum_{U} \mathbf{X}_{U_{i}}
$$

$\left(\partial U_{i} / \partial \mathbf{X}_{H_{i}}^{R}\right)=-U_{C_{i}}\left[\gamma_{H}\right]+U_{E_{i}}\left[d_{H}\right]$ and $U_{G_{i}}=U_{E_{i}} R_{f}$

Algebraic manipulation of the FOC associated with both groups of investors result in the following optimal portfolio demands for the ith investor in $\Omega_{1}$ and $\Omega_{2}$ respectively

$5 A$

$\mathbf{X}_{U_{i}}=\sum_{R}^{*}-1 w_{E V} \mathbf{E}_{U}^{*} \quad i \epsilon \Omega_{1}$

$6 \mathrm{~A}$

$\mathbf{X}_{U_{i}}=\oiint_{U}^{-1}\left[w_{C V_{i}} \Gamma_{H}+w_{E V i} \mathbf{E}_{U}\right]$ and $U_{C_{i}}\left[\gamma_{H}\right]=U_{E_{i}}\left[d_{H}\right] \quad i \epsilon \Omega \mathrm{s}$ 
Now the market clearing conditions are

(i)

$\sum_{i \in \Omega} \mathbf{X}_{K_{i}}=\mathbf{P}_{K} \quad K=S, I, H$

(ii)

$\sum_{i \in \Omega} \mathbf{X}_{H_{i}}^{R}=\mathbf{0} \leftrightarrow \sum_{i \in \Omega} \mathbf{X}_{H_{i}}=\sum_{i \in \Omega} \mathbf{X}_{H_{i}}^{C}$

where condition (ii) reflects the fact that rental in owner-occupied housing is a zero sum game.

Summing the demand equations for the restricted and unrestricted investors in (5A) and (6A) yields

$7 \mathrm{~A}$

$\mathbf{P}=\sum_{R}^{*-1}\left[\sum_{i \in \Omega_{1}} w_{\mathrm{Ev}} \mathbf{E}_{U}^{*}\right]+\mathbb{W}_{U}^{-1}\left\{\left[\sum_{i \in \Omega_{1}} w_{C V_{i}} \Gamma_{H}\right]+\left[\sum_{i \in \Omega_{1}} w_{E V_{i}} \mathbf{E}_{U}\right]\right\}$

If we multiply both sides of equation (7A) by $\aleph_{U}$, this yields the following set of equations:

$8 \mathrm{~A}$

$\Varangle_{A} \mathbf{P}=\sum_{i \in \Omega} w_{E V} \mathbf{E}_{R}$

$9 \mathrm{~A}$

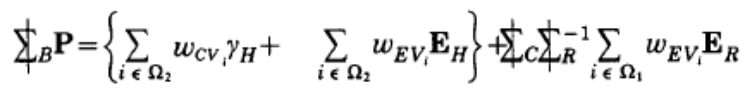

Manipulation of $(8 \mathrm{~A})$ yields the equilibrium return vectors for financial assets and incomeproducing real estate. The return vector for financial assets is

$10 \mathrm{~A}$

$\sum_{i \in \Omega} w_{E V} \mathbf{E}_{S}=a_{11} \mathbf{C}_{S S} \mathbf{P}_{S}+a_{12} \mathbf{C}_{S I} \mathbf{P}_{I}+a_{13} \mathbf{C}_{S H} \mathbf{P}_{H}$

If we multiply both sides of equation (10A) by $\lambda$ then an element of the return vector for

financial assets is the equilibrium price for stock $j$ conditional on rent in the owner-occupied housing market.

$11 \mathrm{~A}$

$E\left(\tilde{R}_{S_{j}}-r_{f}\right)=\left(2+r_{f}\right) \phi_{S}+h M^{*} \operatorname{cov}\left(\tilde{R}_{S_{j}}, \tilde{R}_{M^{*}}\right)$

To obtain the equilibrium condition for income-producing real estate, recall from equation (8A) that 
$12 \mathrm{~A}$

$\sum_{i \in \Omega} w_{E V} \mathbf{E}_{I}=a_{21} \mathbf{C}_{S I} \mathbf{P}_{S}+a_{22} \mathbf{C}_{I I} \mathbf{P}_{I}+a_{23} \mathbf{C}_{I H} \mathbf{P}_{H}$

An element of this vector that follows is the equilibrium price for the $j$ th income-producing

property

$13 \mathrm{~A}$

$E\left(\tilde{R}_{I_{j}}-r_{f}\right)=\left(\frac{L_{I}}{1-L_{I}}\right)+\left(\frac{L_{I}}{1-L_{I}}\right)\left(d_{I_{j}}-r_{f}\right)+h M^{*} \operatorname{cov}\left(\tilde{R}_{I_{j}}, \tilde{R}_{M^{*}}\right)$

with no assumption made that the rental market for housing is in equilibrium. To find the equilibrium housing condition, recall from equation $(9 \mathrm{~A})$ that

$\sum_{B} \mathbf{P}=\left\{\sum_{i \in \Omega_{2}} w_{C V_{i}} \gamma_{H}+\sum_{i \in \Omega_{2}} w_{E V_{i}} \mathbf{E}_{H}\right\}+\sum_{C} \psi_{R}^{-1} \sum_{i \in \Omega_{1}} w_{E V_{i}} \mathbf{E}_{R}$

and

$\sum_{i \in \Omega_{2}} w_{C V_{i}}\left[-\gamma_{H}\right]+\sum_{i \in \Omega_{2}} w_{E V_{i}} \mathbf{E}_{H}^{R}=0$

so adding these two equations together we obtain

$14 \mathrm{~A}$

$\sum_{B} \mathbf{P}=\zeta_{1} \sum_{C} \mathbf{P}_{R}+\zeta_{1} \psi_{C} \sum_{R}^{-1} \psi_{C}^{*} \mathbf{P}_{H}+\sum_{i \in \Omega} w_{E V_{i}}\left[\mathbf{E}_{H}+\mathbf{E}_{H}^{R}\right]$

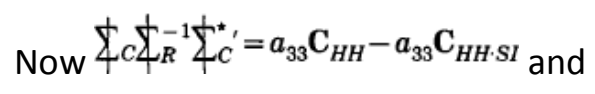

$\sum_{i \in \Omega} \mathrm{w}_{\mathrm{EV}_{i}}=\sum_{i \in \Omega_{1}} w_{E V_{i}}+\sum_{i \in \Omega_{2}} w_{E V_{i}}$

so substitution into equation $(14 \mathrm{~A})$ and then rearranging terms results in

$15 \mathrm{~A}$

$$
\zeta_{2}\left[a_{31} \mathbf{C}_{H S} \mathbf{P}_{S}+a_{32} \mathbf{C}_{H I} \mathbf{P}_{I}+a_{33} \mathbf{C}_{H H} \mathbf{P}_{H}\right]+\left[1-\zeta_{2}\right]\left[a_{33} \mathbf{C}_{H H \cdot S I} \mathbf{P}_{H}\right]=\sum_{i \in \Omega_{2}} w_{E V}\left[\mathbf{E}_{H}+\mathbf{E}_{H}^{R}\right]
$$

If we multiply $h_{2}$ on both sides of equation (15A), then an element of the housing return vector

is

$16 \mathrm{~A}$

$E\left(\tilde{R}_{H_{j}}-r_{f}\right)=\left(\frac{L_{H}}{1-L_{H}}\right)-\left(\frac{L_{H}}{1-L_{H}}\right)\left(d_{H_{j}}-r_{f}\right)+h M^{*} \operatorname{cov}\left(\tilde{R}_{H_{j}}, \tilde{R}_{M^{*}}\right)+\left(h_{2}-h\right) M_{H} \operatorname{cov}\left(\tilde{R}_{H_{j}}, \tilde{R}_{M_{H}} \mid \tilde{R}_{S}, \tilde{R}_{I}\right)$ 
To solve for $h$ and $h_{2}$, we must first obtain the equilibrium condition for the entire market. Equation $(11 \mathrm{~A})$ is multiplied by $P_{S_{j}}$ and then summed over all $j$. A similar logic process is used for income-producing real estate and housing. Next, the results for all asset categories are added together to obtain:

17A

$$
\left[\left(E\left(\tilde{R}_{M^{*}}-r_{f}\right)-\Lambda\right) \div \rho\right]=h(1-w)+h_{2} w \Leftrightarrow\left\{\left[\left(E\left(\tilde{R}_{M^{*}}-r_{f}\right)-\Lambda\right) \div \rho\right]-h\right\} w^{-1}=\left(h-h_{2}\right)
$$

where

$18 \mathrm{~A}$

$-\Lambda=\sum_{j \in B} L_{j}\left(M_{j} / M^{*}\right)\left(d_{M_{j}}-r_{f}\right)-\sum_{j \in B} L_{j}\left(M_{j} / M^{*}\right)-\left(2+r_{f}\right)\left(M_{S} / M^{*}\right) \phi_{S}$ and $w=\left[\rho_{H \mid S I} \div \rho\right]$

Now by definition, $\left(h-h_{2}\right) \geq 0$ and since $w \geq 0$ it follows that

19A

$\left\{\left[\left(E\left(\tilde{R}_{M^{*}}-r_{f}\right)-\Lambda\right) \div \rho\right]-h\right\} \geq 0$

where the strict inequality holds if the owner-occupied housing market is mildly segmented and the equality holds if all asset markets are integrated. Suppose we let

$20 \mathrm{~A}$

$H=\theta\left[\left(E\left(\tilde{R}_{M^{*}}-r_{f}\right)-\Lambda\right) \div \rho\right]$

where $\theta=1$ if markets are integrated and $1>\theta>0$ otherwise. Then it follows that

$21 \mathrm{~A}$

$\left(H-H_{2}\right)=(1-\theta)\left[\left(E\left(\tilde{R}_{M^{*}}-r_{f}\right)-\Lambda\right) \div \rho_{H \mid S I}\right]$

The equilibrium prices for financial assets and income-producing real estate conditional on rental markets thus follows from substituting equation (20A) into equations (11A) and (13A) respectively. The equilibrium price for housing obtains if equations $(20 \mathrm{~A})$ and $(21 \mathrm{~A})$ are substituted into equation (16A). To compute the equilibrium prices given that the rental market for housing is in equilibrium, we use the following rental condition derived from the FOCs and from the aggregation conditions

$22 \mathrm{~A}$

$\sum_{i \in \Omega_{2}} w_{C V_{i} \gamma_{H}}=\sum_{i \in \Omega_{2}} w_{E V_{i}} \mathbf{E}_{H}^{R}$ 
together with the definition for $\varphi_{2}$ to obtain

$23 \mathrm{~A}$

$\left(d_{H_{j}}-r_{f}\right)=\left(\varphi_{2} \gamma_{H_{j}}-r_{f}\right)$

We can substitute equation (23A) into the equation for $-\Lambda$ in equation (18A) to yield

$24 \mathrm{~A}$

$\psi=L_{I}\left(\frac{M_{I}}{M^{*}}\right)\left(d_{M_{j}}-r_{f}\right)+L_{H}\left(\frac{M_{H}}{M^{*}}\right)\left(\varphi_{2} \gamma_{H_{j}}-r_{f}\right)-\sum_{j \in B} L_{j}\left(\frac{M_{j}}{M^{*}}\right)-\left(2+r_{f}\right)\left(\frac{M_{S}}{M^{*}}\right) \phi_{S}$,

which is equation ( 8 ) in the text. The expressions in equation (23A) and (24A) are substituted into the equilibrium results conditional on the housing rental market to obtain the following unconditional equilibrium prices for each asset class. The equilibrium price for stock $j$ is

$25 \mathrm{~A}$

$E\left(\tilde{R}_{S_{j}}-r_{f}\right)=\left(2+r_{f}\right) \phi_{S}+\theta\left[E\left(\tilde{R}_{M^{*}}-r_{f}\right)+\psi\right] \beta_{S_{j}}^{\dagger}$

which is equation (2) in the text. The equilibrium price for the $j$ th income-producing real estate is

26A

$E\left(\tilde{R}_{I_{j}}+r_{f}\right)=\left(\frac{L_{I}}{1-L_{I}}\right)-\left(\frac{L_{I}}{1-L_{I}}\right)\left(d_{I_{j}}-r_{f}\right)+\theta\left[E\left(\tilde{R}_{M^{*}}+r_{f}\right)+\psi\right] \beta_{I_{j}}^{\dagger}$,

which is equation (3) in the text, and the equilibrium price for the jth owner-occupied house is

$27 \mathrm{~A}$

$E\left(\tilde{R}_{H_{j}}+r_{f}\right)=\left(\frac{L_{H}}{1-L_{H}}\right)-\left(\frac{L_{H}}{1-L_{H}}\right)\left(\varphi_{2} \gamma_{H_{j}}-r_{f}\right)+\theta\left[E\left(\tilde{R}_{M^{*}}+r_{f}\right)+\psi\right] \beta_{H_{j}}^{\dagger}+(1-\theta)\left(\frac{1}{1-L_{H}}\right)\left[E\left(\tilde{R}_{M^{*}}+r_{f}\right)+\psi\right] \beta_{H_{j} S I}^{\dagger}$

which is equation (4) in the text.

Portfolio Demands for $\Omega_{1}$ Investors: Recall from (5A) that the portfolio demand for $i \in \Omega_{1}$ is

28A

$\mathbf{X}_{R_{i}}=\sum_{R}^{-1} w_{E V_{i}} \mathbf{E}_{R} \quad i \epsilon \Omega_{1}$

Now if $\mathbf{X}_{S_{\Omega_{1}}}=\sum_{i \in \Omega_{1}} X_{S_{i}}$ and $\mathbf{X}_{I_{\alpha_{1}}}=\sum_{i \in \Omega_{1}} X_{I_{i}{ }^{\prime}}$ then the aggregate portfolio demand for $\Omega_{1}$ investors is

$29 A$

$\mathbf{X}_{\Omega_{1}}=\left(\lambda a_{1}\right)\left\{\mathbf{M P S}+\left(1-L_{H}\right) \mathbf{D P} \mathbf{P}_{\mathrm{H} \cdot \mathrm{I}}+\mathbf{M P I}+\left(\frac{1-L_{H}}{1-L_{I}}\right) \mathbf{D P} \mathbf{P}_{\mathbf{H} \cdot \mathbf{S}}\right\}$ 
which is equation (5) in the text.

Portfolio Demands for $\Omega_{2}$ Investors. Recall from (6A) that the portfolio demand for $i \in \Omega_{2}$ is

$30 \mathrm{~A}$

$\mathbf{X}_{U_{t}}=\oiint_{U}^{-1}\left\{w_{E V_{i}} \mathbf{E}\right\}$

Now if $\mathbf{X}_{k_{\alpha_{3}}}=\sum_{i \in \Omega_{2}} X_{k_{i}} k=S, I, H$ with $\sum_{i \in \Omega_{2}} w_{E V} \mathbf{E}_{R}=\zeta_{2} \downarrow_{A} \mathbf{P}_{\text {ind }} \sum_{i \in \Omega_{2}} w_{E V_{i}}\left[\mathbf{E}_{H}+\mathbf{E}_{H}^{R}\right]=\zeta_{2} \&_{B} \mathbf{P}+\left[1-\zeta_{2}\right] a_{33} \mathbf{C}_{H H \cdot S I} \mathbf{P}_{H}$ then it follows that the aggregate portfolio demand equations for $\Omega_{2}$ investors are

$31 \mathrm{~A}$

$\mathbf{X}_{\Omega_{2}}=\left(\frac{\lambda}{\lambda_{2}}\right) \mathbf{M P}+\left(\frac{\lambda_{2}-\lambda}{\lambda_{2}}\right) \mathbf{H} \mathbf{P}_{\mathbf{H} \cdot \mathbf{I}}-\left(\frac{\lambda_{2}-\lambda}{\lambda_{2}}\right)\left(\frac{1-L_{H}}{1-L_{I}}\right) \mathbf{D P} \mathbf{P}_{\mathbf{H} \mathbf{S}}$

which is equation (6) in the text.

\section{References}

T. Anderson. An Introduction to Multivariate Statistical Analysis. John Wiley and Sons, first edition 1958.

F. Black and M. Scholes. The Effects of Dividend Yield and Dividend Policy on Common Stock Prices and Returns. Journal of Financial Economics 1(1): 1-22, 1974.

J. C. Bosch. Portfolio Choices, Consumption, and Prices in a Market with Durable Assets. Journal of Financial Research 9(3): 239-50, 1986.

M. Brennan. Taxes, Market Valuation, and Corporate Financial Policy. National Tax Journal 23(4): 41728, 1970.

N. Brito. Marketability Restrictions and the Valuation of Capital Assets under Uncertainty, Journal of Finance 32(4): 1109-23, 1977.

J. Diermeier, J. Freundlich and G. Schlarbaum. The Role of Real Estate in a Multi-Asset Portfolio. In T, Sale, editor. Real Estate Investing. Dow Jones Irwin, 1985.

P. Dhrymes. Econometrics: Statistical Foundations and Applications. Springer-Verlag, second edition 1974.

D. Draper and M. C, Findlay, III, Capital Asset Pricing and Real Estate Valuation, AREUEA Journal 10(2): $152-83,1982$.

V. Errunza and E. Losq, International Asset Pricing under Mild Segmentation: Theory and Test. Journal of Finance 40(1): 105-24, 1985. 
D, Geltner. Estimating Real Estate Systematic Risk from Aggregate Level Appraisal-Based Returns, AREUEA Journal 17(4): 463- 81, 1989.

D. Glenn. Super Premium Security Prices and Optimal Corporate Financing Decisions. Journal of Finance 31(2): 506-46, 1976.

S. Grossman and G. Laroque, Asset Pricing and Optimal Portfolio Choice in the Presence of Illiquid Durable Consumption Goods, Econometrica 58(1): 25-52, 1990.

D. Mayers, Non-Marketable Assets and Capital Market Equilibrium under Uncertainty. In M. Jensen, editor. Studies in the Theory of Capital Markets. Praeger, 1972. 